\title{
Evaluation of the City and Guilds Level 3 Adult Numeracy Support Course at Merton College in the UK
}

\author{
Fletcher, J. A. \\ Faculty of Education UCC Cape Coast \& Merton College, Kingston University, UK
}

\begin{abstract}
This paper looks at the evaluation of the Level 3 Certificate in Adult Numeracy Support (City and Guilds 9484) course at Merton College. The latter is a general further education (FE) college and the main provider of post-16 education and training in the London Borough of Merton. The College also runs a number of higher education (HE) courses. The course was introduced into the School of Community Education following the college's successful bid to run a Level 3 course in numeracy in partnership with other colleges in the South London learning Partnership. The main objective of the evaluation of the course at Merton College was to find out how the course measured up to the standards specified by the DfES/FENTO Subject Specifications and echoed by City and Guilds in the Course handbook (City and Guilds, 2005) as well as the procedures specified in the Merton College College's Quality Assurance system. It was clear that the team was faced with challenges in understanding the level of the mathematics content required, and of linking this with strategies, methods and skills to teach adult numeracy learners. One critical observation the author made was the team's inability to change the course structure and content to suit the needs of the candidates. One other limitation of the course was the absence of information and computer technology use. Candidates were not introduced to adequate use of information and computer technology (ICT) as part of their learning. The author observes further that initial teacher education is a complex combination of knowledge as it requires specialist knowledge but at the same time much depends on experience and learning on the job. There is little doubt that the lack of thorough and systematic support for trainees in the place of teaching is a profound systemic weakness that impoverishes all teacher education programmes, not just those discussed in this paper
\end{abstract}

Keyword adult numeracy, quality assurance,

\section{Introduction}

Teachers constitute the most important (and perhaps the most expensive) resource in education therefore there is no gainsaying that any educational system is as good as the teachers in it. It follows that the main way of improving the quality of learning that takes place in any educational system is to improve the quality of teaching in that system. One way of improving the quality of teaching is by providing trainee teachers with the opportunity to develop their subject knowledge base in their specialism, and their pedagogical skills and behaviour to enable them to provide quality teaching.

This paper looks at the evaluation of the Level 3 Certificate in Adult Numeracy Support (City and Guilds 9484) course at Merton College. The latter is a general further education (FE) college and the main provider of post-16 education and training in the London Borough of Merton. The College also runs a number of higher education (HE) courses. The Level 3 course is designed to provide teachers of adult numeracy with the knowledge and skills to develop their interest and understanding of the subject by promoting both an awareness of wider social and learning issues related to the development of numeracy skills, and an advanced level of personal numeracy skills.

The course was introduced into the School of Community Education following the college's successful bid to run a Level 3 course in numeracy in partnership with other colleges in the South London learning Partnership. The colleges involved in the partnership aimed to help vocational lecturers to embed numeracy in their vocational areas as well as prepare prospective numeracy specialists for the Level 4 numeracy subject specialist course. The latter aim reflects the view that the content of the Level 3 Certificate in Adult Numeracy Support, in particular 
Unit 1, covers many of the themes and concepts in the Level 4 Certificate for Adult Numeracy Subject Specialist course. The difference is viewed as one of depth only.

At Level 3, candidates are expected to demonstrate a basic understanding and awareness of the knowledge and concepts covered. They should be able to use key terminology and be able to describe the key elements of a concept or theory in terms of its relevance to working with adult numeracy learners. For assessment purposes, candidates are asked to describe or list in their assessments, to reflect on the implications for practice, and to demonstrate their basic understanding when working with learners.

At Level 4, candidates are expected to demonstrate a deeper understanding and confidence with the theories and concepts covered. They should be able to use a broader range of terminology with accuracy and confidence, analyse, compare and discuss concepts and theories, and reflect on their implications for practice. Their understanding should be developed through their personal reading and this reading evidenced in their written assignments. Level 4 candidates are also required to demonstrate they can relate this deeper understanding to practice both in their assignments and in their observed teaching practice (City and Guilds, 2005).

Since the publication of the 'Moser Report' (DfEE 1999), the government has consistently emphasised the need to ensure that all new teachers employed to teach literacy, numeracy and ESOL in Further Education (FE) colleges would be required to hold, or achieve in a specified time, a specialist literacy, numeracy or ESOL teaching qualification. The publication of the DfES/FENTO Subject Specifications for teachers of adult literacy and numeracy (2002) and ESOL (2003) followed as the basis for the new qualifications.

These new specialist qualifications are required alongside a recognised general teaching qualification. The specifications define the knowledge, personal skills and understanding required of teachers of adult literacy, ESOL and numeracy. They are meant to ensure that all new teachers are equipped with the appropriate knowledge, understanding and personal skills in their subject, in order to put them on a par with teachers in any other subject. As mentioned above, the Level 3 course under discussion provides a route to the numeracy specialist qualification.

\section{Rationale}

The main objective of the evaluation of the Level 3 Certificate in Adult Numeracy Support (City and Guilds 9484) course at Merton College was to find out how the course measured up to the standards specified by the DfES/FENTO Subject Specifications and echoed by City and Guilds in the Course handbook (City and Guilds, 2005) as well as the procedures specified in the Merton College College's Quality Assurance system.

The evaluation adopted a multi-methods enquiry approach involving both quantitative and qualitative procedures. Colleagues teaching on the course as well as candidates on the course completed questionnaires and took part in interviews and discussions. In addition to the above, the author also examined course materials, consulted the QA Manager and the Head of school of Community Education who oversees the course.

\section{Course description}

The Level 3 qualification is designed "to develop an awareness of some of the social and educational issues surrounding numeracy and number skills learning and development as well as an advanced level of personal numeracy skills. It is also intended to develop skills in supporting learning at a variety of levels with adult numeracy learners (City \& Guilds, 2005 p.5). The qualification is aimed at Learning Support Assistants and Non-Specialist teachers embedding numeracy in their vocational areas. The former category includes learning support 
assistants working in a workshop environment or a class, as well as assistants working in Learndirect centres supporting learners with online learning. It also includes those whose primary job is to support people with specific learning difficulties or disabilities, or those with special requirements in an educational setting. (City and Guilds op. cit, p.6).

The latter category includes teachers of other subjects who provide embedded adult numeracy support for their learners, either in class or at other arranged times. This might be in colleges, community settings, vocational training or work-based learning. (ibid). The Level 3 specifications are presented in two sections. The first section (social and personal factors affecting learning) deals with an understanding of some of the social and personal contexts that shape number skills learning and development. This includes an understanding of the learning difficulties and disorders that challenge some learners when developing number skills.

The second section addresses personal numeracy skills. This section is split into the following four sub-sections, namely, numbers and numeric operations; measurement, geometry and spatial awareness; statistics; and working with formulas. These subsections are designed to provide opportunities for the candidates to enhance their ability to apply mathematical techniques work with numerical rigour and use appropriate notation and units correctly. It is also expected that at the end of the course, candidates will be able to use techniques to check answers for error, and demonstrate understanding of the most appropriate ICT tools and software to use.

Table 1 below shows the qualification structure of the course under discussion.

Table 1 Qualification Structure of the Level 3 Certificate in Adult Numeracy Subject Support

\begin{tabular}{cll}
\hline $\begin{array}{l}\text { Unit } \\
\text { number }\end{array}$ & Unit title & $\begin{array}{l}\text { Suggested } \\
\text { Practice }\end{array}$ \\
\hline 1 & Social and personal factors affecting learning & $15-25$ hours \\
2 & Numbers, measurement and spatial awareness & $15-20$ hours \\
3 & Statistics & $10-15$ hours \\
4 & Working with formulae & $10-15$ hours \\
5 & Learning support practice (Learning Support Assistants) & $10-15$ hours \\
6 & Learning support practice (Non-Specialist Teachers) & $10-15$ hours \\
\hline
\end{tabular}

Candidates must achieve units 1, 2, 3 and 4, and either Unit 5 or 6 for the award of a full Level 3 Certificate in Adult Numeracy Subject Support.

[Source: City and Guilds, 2005, p.7]

\section{The Trainees}

There were seven trainees enrolled on the course, all white women with ages ranging from 26 to 65. Two of the candidates were vocational lecturers looking to embed numeracy in hairdressing; four supported adult numeracy/ESOL learners in a classroom environment and one worked in a Learndirect environment. Thus the trainees on the course brought with them an enormous range of life experience, different qualifications, and also varying amounts of teaching experience. Within the diversity of the trainees it was possible to identify three different groups. Firstly, the two hairdressing lecturers had substantial teaching experience, and one of them had a 'management' role in her college. Secondly, there were two trainees who had only two years teaching experience and thirdly, two who were novices. It is important to identify these different groups in order to highlight the different needs of the trainees. Prior qualifications also showed great variety and this also justified the use of individual learning plans as discussed below. 


\section{Entry Requirement}

City \& Guilds do not set any formal entry requirements for these qualifications: They observe: "no specific prior qualifications, learning or experience are required for candidates beginning the course, although the nature of both the learning and assessment required for the qualification is such that candidates will need to be able to apply mathematical techniques and communicate in graphical and written forms". (City and Guilds, 2005, p.13).

In line with above, candidates were required have a qualification in English/Literacy and Mathematics/Numeracy, equivalent to at least Level 2 of the National Qualifications Framework e.g. GCSE A-C or a pass in the national adult literacy and numeracy tests. All seven candidates had at least the required prerequisite qualification - one candidate had a degree in Mathematics; one had a degree in Education; one had a degree in Biology, two had Certificate in Education, one had 'A' Level mathematics and also completed the level 2 Adult Leaner Support (C \& G 9295) qualification; and one had GCSE passes (A - C) in 8 subjects including Mathematics and English.

In addition to the entry requirements described above, the team had clear and well thought out initial assessment that was linked to diagnostic assessment (Appendix 1).

The assessment helped provide detailed learner profiles against the Level 3 specifications and other curriculum documents. It helped to identify the trainees' entry skills as well as areas for development, and both informed and helped structure the trainees' individual learning plans (ILPs). As Gary et al (2000) rightly point out, each time a piece of student's work is marked; the teacher is diagnosing the positive and negative features of it in order to help the student improve performance.

Members of the team were also clear about how and when to address issues relating to accrediting prior learning or prior certificated learning. One of the candidates had a degree in mathematics and the team had decided, in accordance with the guidelines provided by the Awarding Body (City and Guilds, op. cit), that the candidate did only Units 1 and 5. Once trainees had been recruited on to the course, the main type of on-course assessment was through classroom formative assessment, lesson observations and reflective diary as described below.

\section{Course Delivery}

With regard to delivery, the focus of the evaluation was

a) on the balance between pedagogic content knowledge (Units 2, 3 and 4), and practical learning support skills (Unit 5); and

b) the relationship between formative and summative assessment

Staffing for the programme was drawn from the School of Community Education (SCE). The author was the Assistant Head of SCE at the time the course was being evaluated. Two members of the course team (who were both also internal moderators of the adult numeracy courses in the college) were mathematics specialists who had substantial experience in mathematics and adult numeracy but had no previous experience in training numeracy teachers. This limitation did not seem to affect their confidence in delivering the 'content' units ( Units 3 and 4) that they were responsible for, although one would argue that the limitation mentioned above may have affected their ability to offer the trainee teachers the flexibility of trying different methods of solving numeracy problems in any situation.

Schulman (1986) identifies three important areas of a mathematics teacher's 'content' knowledge of the subject. These are subject matter knowledge, pedagogical content knowledge and curricular knowledge. Subject matter knowledge is "knowledge of the content of the discipline per se as represented, for example, by Bloom's (1956) cognitive taxonomy. Shulman notes that the ways of discussing subject matter knowledge will be different for different 
subject matter areas but add to his generic account Schwab's (1978) notions of substantive knowledge and syntactic knowledge. The former refers to the key facts, concepts, principles and explanatory frameworks in a discipline whereas the latter talks about the nature of enquiry in the field, and how new knowledge is introduced and accepted in that community).

For Shulman, pedagogical content knowledge consists of "the ways of representing the subject which makes it comprehensible to others ... [it] also includes an understanding of what makes the learning of specific topics easy or difficult (Shulman, op. cit., p. 9).

Using Plato's famous example in which Socrates successfully corrected a slave boy's misconceptions about the relationship between the area of a square and the side of its length (Berk, 2004), one would argue that Socrates was aware of the misconception and was therefore able to help the boy because of his knowledge of mathematics. Socrates' success depended, at the very least, upon his ability both to understand and appreciate (and possibly predict) the boy's responses and thus his readiness to help the boy to correct such responses even if such correction demanded more questioning.

Arguably, only someone with a certain level of knowledge could do this. The slave boy learned an important lesson for himself, but this learning depended on both Socrates' knowing a common misconception and also on his ability to introduce the appropriate 'cognitive conflict' (McClellan, 1994). Thus, Socrates drew on a knowledge base that included, but extended beyond, knowledge of mathematics per se (Schulman, 1986, Ball, 1991).

In other words, the lecturers' limited subject specific pedagogical knowledge may have affected the way they delivered their units. Indeed, the trainees drew a somewhat sharp comparison between the way the author delivered one of the content units (Unit 2) and the way the others did it. This observation seems to endorse Shulman's (1987) position on the attributes of a 'good' mathematics teacher.

\section{Resources}

With regard to resources used to deliver the course, the evaluation sought to:

- Identify the different types of resources that were used to facilitate learning.

- Explore ways in which the resources were adapted to suit the needs of different learners

- Examine how modern technologies enhanced learning (FENTO, D 5).

Resources are a fundamental part of teaching and learning. They allow the lessons to be more interesting, motivating, engaging and effective. However, it is important that the materials developed and used are both varied and appropriately designed to suit learners' needs and abilities. (Wallace, 2001).Teachers have the choice to either adopt existing materials or create their own which can be time consuming, but on the other hand they may be more appropriate to learners as they are specifically designed for the respective group (Reece, \&Walker, 2003).

In nearly all the lessons that the author delivered and those that were observed for the purpose of evaluating the course, the trainers used a combination of resources which undoubtedly added interest and kept trainees actively engaged in the sessions. Apart from the basic resources such as the whiteboard and overhead projectors, the majority of the resources used on the course came from the library. The library had a good selection of CDs and DVDs form the Mathematics Standards Unit and Skills for Life materials that could be adapted for use in the training. As DVDs are visual and auditory, they can generally reach most of the learners to a fair degree.

What was lacking, however, was adequate supply e-learning (interactive) materials. For example, the lecturers had no access to interactive whiteboards nor did they have access to classrooms with computers for all the learners. This meant that although the individual lecturers 
made use of computers in the training, these were used for presentation purposes and also to 'demonstrate' the uses of the various Standards Unit materials. The trainers had very little opportunity to interact with computers and this may have affected how they would use computers in their numeracy teaching and support work.

It is important to highlight the considerable interest in the use of ICT to support the learning of basic skills as a result of research evidence which suggest that computer aided learning enhances learning. For example, the skills for Life strategy (National strategy, 2001) reported that half of the adults with poor basic skills would be motivated to improve their skills of it was through computers

The Learning and Skills Council's Distributed and Electronic Learning Group (2002) also investigated the potential of e-learning to deliver and support learning and identified e-learning as a vital component in learning and skills. They recognised its potential to reach new learners and to deliver learning in areas such as literacy and numeracy skills.

A similar observation was made in the success For All (Department for Education and Skills, 2002) consultant document on the future of Further Education and Training. The document also identified that ICT was a powerful way of motivating learners and delivering learning.

A major government-supported initiative to make vocational e-learning available to the whole population by creating a national network of learning centres through the Learndirect programme. In June 2002 there were 1,691 centres open, delivering 621 e-learning courses and 362,000 learners (Learndirect, 2002). Learndirect is growing very quickly, expanding courses, centres and learners. The number of learners have more than doubled to over 900,000 in 2006 (http://www.learndirect.co.uk/. Accessed 30 $30^{\text {th }}$ May 2006 at 18.50)

A Key objective of Learndirect is to widen participation in learning and it targets many disadvantaged groups and individuals. These groups are often associated with limited access to and use of ICT. As far as the group under discussion is concerned, the limited access to the use of computers in the classroom could affect their interaction with computers significantly.

As Lesgold (2003) observes, when students interact with dynamic computer representations they are having experiences that cannot be reproduced with static textbook diagrams or tooth picks and Styrofoam balls. In the context of the issue under discussions, the aim of using computer representations in the teaching of mathematics is to provide opportunities for interactions with computer programmes that will enhance and enrich the teaching and learning of mathematics. Such interactions can be achieved through activities with individual learners, with small groups or with the whole class using a projector or an interactive whiteboard.

Although it is very difficult to measure the impact of the limited use of computers on the course, given that all the seven candidates on the course successfully completed and achieved, it can be argued that the candidates could have gained more knowledge, skills and confidence in the use of technology if they had been exposed to different mathematics learning programmes on the course either face to face or on-line.

In reviewing studies of the effectiveness of computer - assisted instruction, Clark (1999) argued that to measure technology's impact, we need to compare two sets of teachers (or, ideally, the same teachers with two sets of classes) using the same method with same material, in one case with the material and pedagogy presented by a computer and in the other, by more conventional media.

Today, about seven years after Clark's argument, not many developers and researchers working in the learning technology industry will agree with this design guideline not only because of the number of intervening variables that can make it difficult to measure the 'real' differences (or lack of it) between using technology and not using technology, in the teaching and learning 
process, on a particular course, but such comparative studies tend limit technology based experiences to only interactions that can be provided off-line (Lesgold, 2003)

The suggestion is that the impact of technology is enhanced by on-line interactions. Indeed, There has been an explosion of e-learning in the last ten years or so, making higher education courses available to new populations, such as people working full time, people living far from universities, commuter students and house bound parents, etc. (Shea et al, 2001). On-line enthusiasts wax poetic over the new possibilities of e-learning, the increased one to one interaction with students, the deeper levels of discussion engendered by e-conferencing, and increased student participation (Boshier, 1990; Swan, 2001; Smith et al, 2002).

However, a number of authors including Leventhall (2004) and Smith \& Ferguson ( 2004) have observed that text oriented on-line course management systems do not provide adequate support for mathematics notation, formulas and diagrams, which are the very language of mathematics! Nevertheless, supplementing the traditional face -to-face model of delivery with on-line delivery, for example, can go a long way to enhance teaching and learning of mathematics

\section{Learning Support Practice}

As mentioned above, candidates on the Level 3 course seeking to work in a learning support role are required to work under the guidance of a trained adult numeracy specialist and take Unit 5 as their support practice. Similarly, candidates seeking to work in a non-specialist teaching role are required to have access to guidance from a trained adult numeracy specialist but should take Unit 6 as their support practice

All the candidates on the course had mentors who monitored the candidates' learning support practice, albeit there was an uneven level of work-place support given to the trainees. Two of the trainees said they received very limited support from their mentors during teaching practice. This observation confirmed other findings that point to the inadequate level of work-place support for trainees of further and adult teacher education programmes (Ofsted 2003, Lucas et al 2004). This is hardly surprising because the majority of the trainees were in-service and working already and their timetables were set. This meant support for some of these trainees was constrained by the culture and structures of their organisation. Both trainers and trainees were concerned about this weakness and saw it as one of the biggest challenges that the course faced.

\section{Assessment}

Summative assessment of leaning on the course consisted of the following:

- one externally set and externally marked assignment for Unit 1

- three externally set and internally marked assignments for Units 2, 3 and 4

- portfolio evidence for Units 5 or 6.

- quality assurance provided by the centre and monitored by City \& Guilds' external verification system, to ensure that national standards are maintained. The Units are graded Pass/Refer only.( (City and Guilds, 2003)

As far as Unit 5 or Unit 6 is concerned, candidates were to do a total of 15 hours subject support practice, including some one-to-one support practice and at least 8 hours working with at least two learners at different levels (small group).

Non specialist teachers were required to complete the subject support practice within their core teaching role. For example, a hair dressing lecturer delivering NVQ Level 2 in Hair Dressing 
would be expected to complete the 15 hours as part of their main teaching role, but demonstrate during that period that they were able to work one-to-one and with small groups as the need arises and in accordance with the learners' Individual Learning Programmes (ILPs).

The aim of their role was to work with a subject specialist to plan and identify targets for learners according to identified needs of the core course and the initial assessment reports. Candidates were expected to use this knowledge and understanding to plan and support the learner(s) to access the literacy/ numeracy skills development within the core course content. Additionally, they were expected to be able to demonstrate that they could effectively differentiate and support learners' literacy and numeracy within their core teaching role (City and Guilds, 2003).

Regarding the assessment strategies that were used on the course, all the three lecturers in the course team used a range of assessment activities to assess learning goals and to evaluate their own teaching. Indeed, using assessment to inform instruction is one of the most powerful tools a teacher can use to improve their teaching. It is also one of the most overlooked! Teachers routinely use assessments for a variety of reasons, most often to assign grades and to report students' progress to their parents. However, assessment's real power is its ability to shape and direct classroom instruction but this is frequently untapped. Teachers can learn valuable information about their students' progress and the effectiveness of their teaching methods by examining students' work or products. (Black \& Wiliam,1998).

The team on the course acknowledged this power of assessment and used it to good effect. As far as the summative assessment of learning was concerned, the trainees undertook one externally set assignment that was externally marked, three externally set assignments that were internally marked and a portfolio of evidence covering Unit 5/6. Portfolios and internally marked assignments were checked by the College's Internal Moderator, and then by the External Moderator for City \& Guilds in accordance with City and Guilds' assessment arrangements.

All the seven candidates passed the Unit 1 assessment at first sitting in March, 2006. They also passed the Unit 5/6 assignments and all the six who did the Units 2, 3 and 4 assignments in number, statistics and algebra respectively passed. In other words, both retention and achievement rates on the course under discussion were one hundred percent. These results reflected the group's overall attendance rate of $95 \%$.

\section{Critical evaluation of the course}

It was clear that the team was faced with challenges in understanding the level of the mathematics content required, and of linking this with strategies, methods and skills to teach adult numeracy learners. As mentioned above, two of the lecturers delivering the course found it difficult to integrate 'mathematics content' with 'methodology', instead offering separate sessions to deal with the mathematics content and separate generic teaching sessions with few connections made between them. There were also examples of cases where the candidates felt (and this was confirmed by the author) that at least one of the other two lecturers was overpitching the level.

The programme was organised so that numeracy, literacy and ESOL trainees followed a part common route which was relevant to trainees in both areas. Thus the numeracy trainees were included in a common core of studies with literacy and ESOL trainees. This design provided opportunities for the numeracy group to understand literacy and ESOL issues but in the candidates' view, this 'amalgamation' went on for too long. The numeracy group, in particular, wanted to be in a separate group in order to consider more numeracy issues. 
One of the candidates struggled with her mathematics a bit and probably shouldn't have been admitted on to the course. This candidate was admitted not so much because the college put pressure on the team to admit the candidate although the latter had inadequate personal skills and little experience of teaching, but the candidate in question was an existing teacher who needed the qualification. Furthermore, the team was required to meet the conditions for the grant for running the course which meant that candidates living or working in the South London Learning Partnership (SLLP) could have access to the if they were already teaching numeracy or embedding numeracy in their vocational area.

One critical observation the author made was the team's inability to change the course structure and content to suit the needs of the candidates. Indeed, as a result of using course regulations prescribed by the City and Guilds as an awarding body, the team found it quite difficult to innovate. The team felt that the content of the Unit 3 assignment, for example, was inappropriate but could not do anything about it but set it as it was. The team felt that the fact that they did not have any influence on the summative assessment was a significant limitation of the course. The situation would have been different if the college was in a position to award the certificate for the course and could therefore influence the assessment of the course. Indeed, by defining the framework for the college, the awarding body effectively interpreted how the standards and specifications were to be used and the team played very little mediating influence between the regulatory framework and the trainees on the course. (Lucas et al 2004).

One of the key issues is the limited pedagogical knowledge of some of the members of the delivery team. Bernstein (2000) describes how two 'different' types of knowledge can be 'recontextualised'. He distinguishes between academic or theoretical knowledge and knowledge acquired from experience. Bernstein refers to the latter as 'horizontal knowledge' as it is related to the specific contexts or situations in which it is acquired. This important type of knowledge tends to be based on 'what works', and draws on individual experience or practice without accessing codified or expert knowledge. In contrast, the subject knowledge in mathematics is specialist disciplinary knowledge which, unlike horizontal knowledge, is not necessarily based on experience. It is de-contextualised generic knowledge. Bernstein refers to this as 'vertical knowledge'. Using Bernstein's distinctions, some members of the team had rich 'vertical knowledge' but limited 'horizontal knowledge'.

The problem according to Bernstein is how to bring the two types of knowledge together and therefore 're-contextualise' knowledge. Re-contextualisation means relating subject knowledge (vertical) and knowledge associated with practical pedagogy (horizontal) together in ways that enhance practice.

Another way of looking at re-contextualisation is to examine Shulman's (1987) idea of 'transformation'. Shulman produced seven categories when analysing the knowledge base of schoolteachers. These are content knowledge, general pedagogic knowledge, curriculum knowledge, knowledge of the learners, knowledge of educational contexts, knowledge of educational ends and pedagogical content knowledge. It is the pedagogical content knowledge - the 'expert' knowledge which is an amalgam of the other categories of knowledge and experience, which in Shulman's view, enhances practice. It is a complex construction of reality that fits the experience of context, knowledge of learners, knowledge of pedagogy and of subject, content and curriculum knowledge. It is knowledge that is 'fit for purpose'! (Shulman, 1987). Lacking such knowledge could significantly affect a teacher's performance

One other limitation of the course was the absence of information and computer technology use. Candidates were not introduced to adequate use of information and computer technology (ICT) as part of their learning. Not only was ICT not used adequately by trainers, no evidence was found of the independent IT learning done by the candidates helping them to rise to or appreciate the challenge of new technology, and integrate ICT more effectively in their own 
practice. This reflects other research that shows generally how scarce ICT use is in literacy, numeracy and ESOL courses. (Mellar et al, 2004)

\section{Recommendations}

The first thing that needs reviewing is the entry requirement. There is the need to have clear and well thought out entry criteria that are linked to diagnostic and initial assessment. This selective approach can greatly influence the profile of trainees on the programmes and the way the course is organised.

The second area that needs looked at is that of the team's expertise. It can be argued that the movement from novice to expert teacher can be seen as the result of the re-contextualisation of horizontal and vertical knowledge. The key then lies in the 'transformation' from content knowledge into a pedagogy that is adaptive and meets the learners needs. This is the essential nature of pedagogical content knowledge. It is recommended that those who teach on the course should undertake at least the level 4 numeracy subject specialist course to get more familiar with ways in which they can integrate numeracy 'content' and 'methodology'.

The third area for improvement is the use of Information Learning Technology (ILT). As far as incorporating IILT is concerned, the course team can make use of the Blackboard facilities the college has to enhance learning. Blackboard has a portal area, which provides some basic general functions, including access to a course area. The course area becomes a virtual learning environment, where lecturers and students can exchange ideas outside the classroom. Students have a private folder, and a drop-box system allows file exchange including comments with tutor. External access to personal folders is possible and this further enhances communication between course teams and learners.

\section{Conclusion}

A number of issues have been raised by the discussion above, particularly the balance between subject and pedagogical knowledge and the whole issue of how teacher training teams are faced with the challenge of coping with the ever increasing regulatory requirements from initial teacher training awarding bodies.

As discussed above, initial teacher education is a complex combination of knowledge as it requires specialist knowledge but at the same time much depends on experience and learning on the job. There is little doubt that the lack of thorough and systematic support for trainees in the place of teaching is a profound systemic weakness that impoverishes all teacher education programmes, not just those discussed in this paper.

Teaching practice in the workplace is a crucial learning zone for trainee teachers, where new learning should take place, where knowledge is changed and where trainees can begin to 'make sense' of knowledge. There is no doubt that through participation in the workplace, trainees do learn. Indeed, if the purpose of teacher education is to prepare trainees for a changing role, to improve quality and to innovate, then a more expanded notion of mentoring and learning through teaching practice or work-based learning is required.

This more expanded notion of the adult basic skills teacher includes broadening their forms of expertise to include resource-based learning, flexible modular curriculum design, offering advice and guidance to individual students, and maximising the potential of information and computer technology as a resource for learning.

Furthermore, literacy, numeracy and ESOL teachers need to understand how their specialism relates to the curriculum as a whole. This is due to the growing overlap between teaching and learning that cuts across subject boundaries, as many 'subject specialists' in the sector now teach on more than one type of programme. This is particularly true in the case of numeracy, 
literacy and ESOL, where learning can be embedded within other curricula, vocational programmes and workplaces.

This is not to suggest that knowledge of the subject matter being taught is not important, and the discussion above has indicated that all the trainees on the course under discussion benefited from improving their subject knowledge. There is clearly a relationship between how something is taught and the knowledge the person teaching it possesses (Watkins and Mortimer 1999).

The point that is being emphasised is the importance of moving beyond the 'top up' model of teaching numeracy. There is the need for a more expanded definition of the forms of specialisation and expertise than are normally associated with teaching numeracy. There is the need for numeracy teachers to acquire all of the Shulman's (1987) seven types of knowledge in order to provide opportunities for the trainees they teach to 're-contextualise' their knowledge.

\section{Reference}

Adult Literacy and Numeracy Skills London. Department for Education \& Skills

Ball, D. L. (1991). Research on teaching mathematics: Making subject-matter knowledge part of the equation. In J. Brophy (Ed.), Advances in research on teaching: Teacher's knowledge of subject matter as it relates to their teaching practice (Vol. 2, pp. 1-48). Greenwich, CT: JAI Press

Berk, S (2004) Greece and Rome to 30 BC Goleta, USA: World Peace Communications

Bernstein, B (2000) Pedagogy, Symbolic Control and Identity: Theory, Research and Critique. London: Taylor and Francis

Black, P and Wiliam, D. (1998) "Inside the Black Box: Raising Standards Through Classroom Assessment," Phi Delta Kappan,

Boshier, R. (1990). Socio-psychological factors in electronic networking. International Journal of Lifelong Education, 9(1), 49-64.

Clark, R (1999). Building Expertise. Washington, DC: International Society for Performance Improvement

DfEE (1999) The 'Moser Report' Improving Literacy and Numeracy: A fresh Start. Sudbury: Department for Education and Employment.

Gary D, Griffin C, and Nasta T (2000) 'Training to Teach in Further and Adult Education', Cheltenham: Stanley Thornes Publishers Ltd

Learndirect (2002) At: http:www.ufiltd.co.uk/press/facts/default.asp

Learning and Skills Council (2002) Distributed and Electronic Learning Group Report,. Coventry:LSC.

Lesgold, A. (2003) Evaluation Educational Technology. Teachers College Columbia University.

Leventhall, L. (2004). Bridging the gap between face to face and online maths tutoring. Paper presented at the International Congress of Mathematics Education-10, Copenhagen, Denmark, July 2004.

Lucas, N,. Casey, H., Loo, S., McDonald, J., Young, M and Giannakaki, M. (2004) New Initial Teacher Education Programmes for Teachers of Literacy, Numeracy and ESOL 2002/3. An Exploratory Study. National Research and Development Centre: London

McClelland, D. (1984). Human Motivation. Cambridge, MA: Cambridge Press. 
Mellar, H., Kambouri, M., Sanderson, M., and Pavlou, V. (2004). ICT and adult literacy, numeracy and ESOL. London: NRDC

National Strategy (2001) Skills Life: The National Strategy for Improving

OFSTED (2003) The Initial Training of Further Education Teachers: A Survey. HMI 1762. London: OFSTED

Reece, I \& Walker, S (2003) Teaching, Training and Learning, 4th edn. U.K, Business Education.

Shea, P., Swan, K., Fredericksen E., and Pickett, A. (2001). Student satisfaction and reported learning in the SUNY Learning Network. In Elements of quality online education, Volume 3 in the Sloan-C series, The Sloan Consortium New York.

Shulman, L. (1986) 'Those who understand, knowledge growth in teaching'. Educational Researcher 15(2), pp 4-14.

Shulman, L. (1987) 'Knowledge and Teaching: Foundations of the new reform'. Harvard Educational Review, Vol 57, No1, pp1-22

Smith, G.G. \& Ferguson. D. (2004). Learning math problem-solving in online courses. Proceedings of E-Learn 2004: World Conference on E-Learning in Corporate, Healthcare \& Higher Education, Washington, DC.

Smith, G.G., Ferguson, D. \& Caris, M. (2002). Teaching online versus face-to-face. Journal of Educational Technology Systems, 30(4), 337-364.

Swan, K. (2001). Immediacy, social presence, and asynchronous discussion. In Elements of quality online education, Volume 3 in the Sloan-C series, The Sloan Consortium New York.

Wallace S, 2001,_Teaching and Supporting Learning in Further Education $2^{\text {nd }}$ edn. Great Britain, Matters Ltd.

Watkins, C. and Mortimore, P. (1999), 'Pedagogy: What Do We Know?' In Mortimore, P. (ed) Understanding Pedagogy and Its Impact on Learning. London: Sage. 